\title{
Well-to-Wheel Analysis of Electric and Hydrogen Light Rail
}

\author{
E. Matthew Washing, M.S. \\ Srinivas S. Pulugurtha, Ph.D., P.E. \\ The University of North Carolina at Charlotte
}

\begin{abstract}
The application of renewable energy technologies to rail transit should be evaluated on a comprehensive energy pathway efficiency basis to ensure that the renewable energy technology is truly beneficial. One such method is the well-to-wheel analysis method, which combines the energy efficiencies of each component of the energy pathway into a single energy efficiency value. The focus of this paper is on well-to-wheel analysis of electric and hydrogen light rail. The inefficiencies of the hydrogen train's power plant and hydrogen production process are apparent in the hydrogen train's well-to-wheel efficiency value of 16.6-19.6\%. The electric train, due to improved pathway efficiencies, uses substantially less feedstock energy with a well-to-wheel efficiency value of $25.3 \%$. While this result is specific to Charlotte, North Carolina, the electric train efficiency is influenced by the main source of electricity production-it is $24.6 \%$ in Cleveland, Ohio (coal heavy) and $50.3 \%$ in Portland, Oregon (hydroelectric heavy).
\end{abstract}

Key words: Light rail, electricity, hydrogen fuel, well-to-wheel analysis

\section{Introduction}

Rail in the United States is in the midst of a revival for both freight and passenger rail. The revival and stricter air quality standards prompted research into the application of renewable energies for railroad traction. Hydrogen fuel cells are becoming more cost-competitive with conventional power sources and maintain key advantages such as zero-emissions, little wayside infrastructure, and an abundance of hydrogen in the environment. Passenger rail, especially intra-city rail, in the United States is largely electrified, but hydrogen fuel cells would enable passenger trains more autonomy and a reduction of wayside infrastructure and maintenance costs. To evaluate the application of hydrogen fuel cells to light rail, it is useful to compare the well-to-wheel energy efficiency of the various traction power systems. A well-to-wheel analysis considers the energy efficiency of each step in the energy change and power production component. A well-to-wheel analysis of a concept hydrogen light rail train has not been researched previously. This 
paper focuses on well-to-wheel analysis of hydrogen light rail transit system and compares it with an electric light rail system.

The motivation for using hydrogen as an energy carrier is two-fold. There are substantial potential benefits, both environmentally and economically, in using hydrogen as an energy carrier. Hydrogen is an energy carrier, which is a very important distinction when considering hydrogen as a fuel source. To use hydrogen for power generation, energy input is required to make hydrogen useful. Various feedstocks, primarily fossil fuels, are responsible for imbuing hydrogen with energy. The use of a renewable feedstock, such as wind or hydroelectric energy, permits hydrogen to be an entirely emission-free energy source. Hydrogen is also a very common element and is not geographically concentrated like fossil fuels. Hydrogen could revolutionize the energy market by shifting the pricing power to consumers rather than suppliers.

Conversely, hydrogen as an energy carrier for most applications is redundant. For hydrogen to be a worthwhile energy carrier, it should be produced by renewable energy. In this case, the renewable energy is already in the form of an energy carrier, electricity. Further transformation of the renewable energy into stored chemical energy adds complexities that require energy. The energy requirements to produce, package, distribute, store, and transfer hydrogen are not small. Well-to-tank analysis, which evaluates the energy consumption of the entire production pathway, indicates that approximately $0.35-0.40$ units of energy are expended for every unit of hydrogen energy available. Alternatively, electricity only requires 0.1 units of energy for each unit of electricity produced (Hoffrichter 2013; Bossel and Eliasson 2003).

For these reasons, hydrogen as an energy carrier in most conventional stationary applications is inappropriate. Electricity is a far more logical and efficient energy carrier in stationary applications. Hydrogen's niche as an energy carrier is limited to roles that require mobility and zero emissions at the point-of-use. In this arena, batteries are much more common and widely available. Batteries, however, suffer from their own drawbacks: they have notoriously poor life cycles, low energy density per unit mass, and lengthy recharge times. Hydrogen offers the advantage of an improved life cycle and energy density and refill time comparable to liquid fossil fuels.

\section{Literature Review}

Hydrogen as an energy carrier for rail applications is relatively novel. Like other transport applications of hydrogen fuel cells, it is beginning to gain more recognition and plausibility. Research surrounding hydrogen as an energy carrier for rail applications has been conducted with simulations and real-world demonstrations. To date, hydrogen has been successfully implemented in a variety of rail applications, and practical feasibility has been demonstrated for intercity passenger rail through the use of simulations.

One of the earliest hydrogen-powered rail vehicles was designed as a mining locomotive. The project, under the management of "Vehicle Projects," was motivated by the mining industries' need for a zero-emission, safe, powerful, and productive locomotive (Miller and Barnes 2002). Like indoor utility vehicles, mining locomotives operate in environments that require several safety considerations. Mining locomotives are mostly 
associated with coal and, as a result, have strict health and safety standards to satisfy. Diesel-electric locomotives are inappropriate for mining applications because of the emissions at the point-of-use, and battery-powered locomotives are impractical because of their lack of productivity (Miller and Barnes 2002). Hydrogen fuel cells were seen as an opportunity to satisfy the mining regulations while allowing mines to operate productively without exorbitant costs.

Beyond utility-related projects, hydrogen also has been tested for use in a variety of other rail applications. Another hydrogen retrofit project involved a Burlington Northern Santa Fe switcher locomotive. Switcher locomotives are used for train assembly, often in rail yards and, as a result, operate a rigorous duty cycle. "Vehicle Projects" managed the project that converted an existing diesel-electric switcher locomotive to a hydrogenhybrid locomotive. The hydrogen-hybrid weighs 127 tonnes, is able to produce $250 \mathrm{~kW}$ of continuous power, and has transient power greater than one $\mathrm{mW}$. The motivation for this retrofit was the need to reduce rail yard emissions (particularly at seaports), reduce emissions at point-of-use, create a mobile power source for disaster relief and military applications, and reduce foreign energy reliance. For a switcher locomotive, up to $90 \%$ of operating time may be spent idling, so emission-free power generation can substantially reduce unnecessary emissions (Miller et al. 2007).

Simulations of a diesel-electric commuter line in the United Kingdom demonstrated the ability of a hydrogen-powered and hydrogen-hybrid train to operate the route with greater efficiency and less greenhouse gas emissions. The increase in volume and weight considered could be accommodated on the train model used for simulation. It was concluded that hydrogen is a technically feasible propulsion system for trains (Hoffrichter 2013). The route studied by Hoffrichter (2013) had low passenger volume and was uneconomical to electrify but would still need to meet stricter emission standards in the future. In this instance, the use of hydrogen as the prime mover is suggested to be more economical than electrification and is able to achieve zero point-of-use emissions.

The first hydrogen-hybrid propulsion system for rail transit began operation in the island nation of Aruba in December 2012 (altenergymag.com 2013). Owing to abundant and reliable wind energy, the streetcars of Aruba's capital, Oranjestad, are powered by $100 \%$ clean and renewable energy. The streetcars use a combination of power generation from on-board batteries and hydrogen fuel cells. The hybrid nature of the streetcars allows the system to improve its energy efficiency through regenerative braking. The fuel cell serves to augment the batteries during high power output and when the battery is close to depletion. In total, the hybrid system is far more efficient than any other fossil-fueled propulsion system and retains the autonomous, catenary-free characteristics of diesel-electric trains.

A method used in previous studies to evaluate the full energy pathway efficiency is the well-to-wheel analysis, which is separated into a well-to-tank and tank-to-wheel portions (TIAX LLC 2007). For rail, this method has been used to compare the energy efficiency and emission production of different propulsion systems (Hoffrichter 2013). The energy efficiency is a function of the efficiency of the supply chain of energy and the vehicle's drive train. This analysis determines how much energy from the well, or initial extraction 
of the fuel from nature, is required to provide one unit of energy at the wheel. The emission analysis determines the amount of greenhouse gas emissions associated with the entire pathway of the energy from the well to the wheel (TIAX LLC 2007).

\section{Methodology}

A description of methodology adopted in this research is discussed in this section.

\section{Study Model}

This study is based on existing characteristics associated with the Blue Line Extension in Charlotte, North Carolina, the Blue Line Extension rolling stock, and a concept hydrogen light rail train. The Blue Line Extension is a 9.3-mile-long urban light rail line with 11 stops. The Siemens S70, a light rail vehicle in the United States, is the rolling stock for the Blue Line Extension. Normal operation on the line includes a three-car consist with 7.5-minute headways. The selection of the light rail in Charlotte for the study context has clear implications on the results, and the results will certainly vary for different study contexts.

\section{Well-to-Wheel Analysis}

To complete the well-to-wheel analysis, a basic model of a hydrogen light rail train was necessary. Since hydrogen light rail trains do not exist currently, a concept hydrogen light rail train was developed from existing technologies. The well-to-wheel analysis was, therefore, limited by the assumptions made in developing the concept hydrogen light rail train, although the assumptions are considered to be conservative and realistic.

Based on previous research and development of hydrogen locomotives, several components are necessary to conceptually design a hydrogen light rail train using a conventional light rail train as a base model. A hydrogen light rail train differs from a conventional light rail train in its propulsion system, energy carrier storage system, energy carrier transport system, and energy carrier production system. The concept designs for the hydrogen light rail train are guided by current hydrogen production, hydrogen storage, and hydrogen fuel cells. Each system is based on products that are available for consumer purchase at the time of this writing (August 2014).

The efficiency factors, used to track the energy throughout the entire energy pathway, are based upon a chemical fuel's heating value (U.S. Department of Energy 2012). Each chemical fuel has two heating values-a lower heating value (LHV) and a higher heating value (HHV). The LHV is also referred to as the net calorific value because it accounts for the heat released during the combustion of the fuel less the latent heat of vaporization of water (U.S. Department of Energy 2012). The HHV, or gross energy, takes into account the latent heat of vaporization of water. The HHV is a more complete measure of heat because it includes heat stored in the form of water vapor. However, when computing the energy inputs required based on efficiency factors, the LHV is recommended because it represents the energy available for work (Clarke Energy 2013). For this reason, efficiency factors are given in terms of the LHV.

\section{Hydrogen Production and Transport}

Natural gas reforming is currently the most efficient, cost-effective, and common method to produce hydrogen (Alternative Fuels Data Center 2014). Initially, a synthesis gas is 
formed as a product of natural gas reacting with high temperature steam. The synthesis gas is composed of hydrogen, carbon monoxide, and trace amounts of carbon dioxide. Next, the carbon monoxide can be used in a second reaction involving water, which produces additional hydrogen and carbon dioxide (Alternative Fuels Data Center 2014). The two reactions that serve as the basis of natural gas steam reforming are shown as Equation 1 and Equation 2 (Air Products 2013).

$$
\begin{aligned}
& \mathrm{CH}_{4}+\mathrm{H}_{2} \mathrm{O}->3 \mathrm{H}_{2}+\mathrm{CO} \text { (methane reforming) } \\
& \mathrm{CO}+\mathrm{H}_{2} \mathrm{O}->\mathrm{H}_{2}+\mathrm{CO}_{2} \text { (water gas shift) }
\end{aligned}
$$

The well-to-wheel emission analysis is dependent on the energy mix, or the method by which the energy is produced. In the case of hydrogen and electricity, both are an energy carrier, and thus, require a source of energy. Duke Energy supplies electricity in Charlotte (the location of choice for the concept hydrogen and electric light rail train to operate), and the energy mix for North Carolina in shown in Table 1. Hydrogen may be produced in a variety of methods, but for the purpose of this research, the most successful method of production was steam-methane reforming (SMR). Distributed SMR, specifically, was chosen as the hydrogen production method.

TABLE 1.

\begin{tabular}{|l|c|c|}
\hline \multicolumn{1}{|c|}{ Feedstock } & $\begin{array}{c}\text { Contribution to } \\
\text { Electricity Generation }\end{array}$ & $\begin{array}{c}\text { Gaseous Hydrogen } \\
\text { Production via SMR }\end{array}$ \\
\hline Coal & $38.5 \%$ & $3.2 \%^{3}$ \\
\hline Nuclear & $31.9 \%$ & $2.7 \%^{3}$ \\
\hline Natural gas & $24.5 \%$ & $93.7 \%^{4}$ \\
\hline Hydroelectric & $2.5 \%$ & $0.2 \%^{3}$ \\
\hline Other renewables & $2.6 \%$ & $0.2 \%^{3}$ \\
\hline
\end{tabular}

1 U.S. Energy Information Administration 2014.

${ }^{2}$ Elgowainy, Han, and Zhu 2013.

${ }^{3}$ Used to generate electricity necessary for SMR.

${ }^{4} 91.7 \%$ (SMR), $2.0 \%$ (electricity generation).

SMR may be small-scale or large-scale, which allows hydrogen to be produced on-site or off-site, respectively. If produced off-site at a large industrial SMR plant, the hydrogen must be transported to the final destination, usually by truck or pipeline. Until hydrogen becomes a widely-used energy carrier, distributed SMR plants are the most cost-effective method of hydrogen production (Ogden 2002). Distributed SMR plants can be located near the point of use and integrated into the refueling infrastructure. The downside to distributed SMR is the reduced energy efficiency, compared to centralized SMR. As a result, the use of a distributed SMR for analysis is a conservative assumption. Currently, hydrogen can be produced in a more efficient way than distributed SMR, but the transportation logistics are not realistic. By choosing distributed SMR, the most common method of hydrogen production is used and the logistical challenge of hydrogen transport is avoided. In the authors' opinion, distributed SMR is most likely to be designed as the hydrogen production and transportation mode if a hydrogen light rail system were to be implemented at the time of this writing (August 2014). The efficiency factors for a distributed SMR plant are used for the well-to-wheel emission analysis. 
Based on the energy mix for North Carolina electricity, a weighted efficiency factor that incorporates the LHV efficiency factor for energy generation, the LHV efficiency factor for the recovery and transport of the energy was computed. In computing a total weighted LHV efficiency for the recovery, transport, and generation of North Carolina electricity, the well-to-wheel emission analysis is simplified. Table 2 shows the formulation of the weighted LHV efficiency factor.

TABLE 2.

Total Weighted LHV Efficiency for North Carolina Electricity Feedstock: Recovery, Transport, and Generation

\begin{tabular}{|l|c|c|c|c|}
\hline \multicolumn{1}{|c|}{ Feedstock } & Electricity Mix ${ }^{1}$ & $\begin{array}{c}\text { LHV Generation } \\
\text { Efficiency }^{2}\end{array}$ & $\begin{array}{c}\text { LHV Recovery } \\
\text { and Transport } \\
\text { Efficiency }^{2}\end{array}$ & Weighted Score \\
\hline Coal & $38.5 \%$ & $36 \%$ & $99 \%$ & $13.7 \%$ \\
\hline Nuclear & $31.9 \%$ & $34 \%$ & $95 \%$ & $10.3 \%$ \\
\hline Natural gas & $24.5 \%$ & $51 \%$ & $95 \%$ & $11.9 \%$ \\
\hline Hydroelectric & $2.5 \%$ & $90 \%$ & - & $2.2 \%$ \\
\hline Other renewables & $2.6 \%$ & $35 \%$ & - & $0.9 \%$ \\
\hline \multicolumn{2}{|c|}{ Total LHV Efficiency for Electricity Generation } & $\mathbf{3 9 . 0 \%}$ \\
\hline
\end{tabular}

${ }^{1}$ U.S. Energy Information Administration 2014.

${ }^{2}$ Hoffrichter 2013.

The weighted score in Table 2 is a function of the electricity mix, generation efficiency, and recovery and transport efficiency. The purpose in computing a weighted score is to produce a single efficiency value that takes into account the respective efficiencies of each of the energy sources. The method to compute the weighted score is outlined in Equation 3.

$$
\sum_{i=0}^{n} \boldsymbol{E} \boldsymbol{M}_{\boldsymbol{n}} * \boldsymbol{G} \boldsymbol{E}_{\boldsymbol{n}} * \boldsymbol{R} \boldsymbol{T}_{\boldsymbol{n}}(\text { Weighted Score })
$$

where, $\mathrm{EM}_{\mathrm{n}}$ is the electricity mix of the $\mathrm{n}^{\text {th }}$ energy source in percentage, $\mathrm{GE}_{\mathrm{n}}$ is the LHV generation efficiency of the $\mathrm{n}^{\text {th }}$ energy source in percentage, and $R T_{n}$ is the LHV recovery and transport efficiency of the $\mathrm{n}^{\text {th }}$ energy source in percentage.

The weighted LHV efficiency for the hydrogen feedstock is computed similarly and summarized in Table 3. The weighted efficiency factor for electricity feedstock and hydrogen feedstock, as seen in Tables 2 and 3, are clearly a function of the feedstock mix. The feedstock mix is specific to the North Carolina study context and the distributed SMR hydrogen production method. Consequently, locations with a higher coal or nuclear share than North Carolina are likely to have a reduced electricity feedstock efficiency factor. Likewise, hydrogen production methods such as coal-powered electrolysis would reduce the feedstock efficiency factor for hydrogen production. The assumptions made in this study are specific to the study context, but may easily be varied under different scenarios. 
TABLE 3.

Total Weighted LHV Efficiency for Hydrogen Feedstock: Recovery, Transport, and Generation

\begin{tabular}{|l|c|c|c|c|}
\hline \multicolumn{1}{|c|}{ Feedstock } & $\begin{array}{c}\text { Hydrogen } \\
\text { Feedstock Mix }\end{array}$ & $\begin{array}{c}\text { LHV Generation } \\
\text { Efficiency }\end{array}$ & $\begin{array}{c}\text { LHV Recovery } \\
\text { and Transport } \\
\text { Efficiency }^{2}\end{array}$ & Weighted Score \\
\hline Coal & $3.2 \%$ & $36 \%$ & $99 \%$ & $1.1 \%$ \\
\hline Nuclear & $2.7 \%$ & $34 \%$ & $95 \%$ & $0.9 \%$ \\
\hline Natural gas & $93.7 \%$ & $51 \%$ & $95 \%$ & $45.4 \%$ \\
\hline Hydroelectric & $0.2 \%$ & $90 \%$ & - & $0.2 \%$ \\
\hline Other renewables & $0.2 \%$ & $35 \%$ & - & $0.1 \%$ \\
\hline \multicolumn{2}{|l}{ Total LHV Efficiency for Hydrogen Feedstock } & $\mathbf{4 7 . 7 \%}$ \\
\hline
\end{tabular}

${ }^{1}$ Elgowainy, Han, and Zhu 2013.

${ }^{2}$ Hoffrichter 2013.

\section{Hydrogen Storage}

Hydrogen storage as a gas, although less concentrated on a volume basis, is preferred in the transport industry because of minimal weight. For rail, where storage of fuel is not strictly limited by volume or weight, gas storage of hydrogen is acceptable. For transport applications, gaseous hydrogen storage is usually 350-bar or 700-bar, with the preference being 700-bar vessels. In particular, Type IV vessels are most applicable to the transport application. Type IV vessels are characterized by a polymeric liner fully wrapped with a fiber-resin composite with a port built into the structure of the vessel (Barral and Barthelemy 2006). Type IV vessels can withstand very high pressures without adding considerable weight.

For a given quantity of hydrogen, composite tanks have the advantage of less volume and less weight. The trend for the automotive industry, the chief promoter of hydrogen storage research, is 700-bar composite tanks (Bakker 2010). The drawback in pressurizing a gas is the loss of energy content due to the pressurization. As a result, more energy is required to fill a $4 \mathrm{~kg}$ 700-bar composite vessel compared to a $4 \mathrm{~kg}$ 200-bar standard vessel. Compared to a 350-bar vessel, a 700-bar vessel requires approximately 10-12\% additional compression energy (Sirosh 2013; Mao 2010). The volumetric increase, 55\%, exceeds the additional compression energy by such an extent that the additional energy loss is worthwhile (Mao 2010).

Since hydrogen's energy content per unit of volume is a fraction of conventional liquid fossil fuels, such high pressures are required to minimize the volume requirements of the storage system and maximize the range of the vehicle. The characteristics of a modern 700-bar vessel for hydrogen are listed in Table 4. These characteristics are the basis for the hydrogen storage component design.

TABLE 4.

Parameters of a Type IV 700bar Hydrogen Vessel

\begin{tabular}{|l|c|}
\hline \multicolumn{1}{|c|}{ Parameter } & Value \\
\hline Useable storage capacity & $5.6 \mathrm{~kg} \mathrm{H}$ \\
\hline Gravimetric capacity & $4.2 \%$ \\
\hline Gravimetric density ${ }^{1}$ & $33.3 \mathrm{kWh} / \mathrm{kg}$ \\
\hline Vessel weight with $5.6 \mathrm{~kg} \mathrm{H}_{2}$ & $112 \mathrm{~kg}$ \\
\hline Volumetric capacity & $26.3 \mathrm{~kg} \mathrm{H}_{2} / \mathrm{m}^{3}$ \\
\hline Vessel volume & $0.22 \mathrm{~m}^{3}\left(7.77 \mathrm{ft}^{3}\right)$ \\
\hline Storage cost & $\$ 18.7 / \mathrm{kWh}^{2}$ \\
\hline
\end{tabular}

1 SUSY 2012.

Source: Argonne National Laboratory 2010 


\section{Hydrogen Propulsion System}

Regardless of the production method of hydrogen, it may be used in a fuel cell to produce energy. There are other methods of producing energy from hydrogen, such as internal combustion engines, but their energy efficiency is unable to match that of fuel cells (U.S. Department of Energy 2014). Perhaps the most common fuel cell today is the polymer electrolyte membrane (PEM) fuel cell. PEM fuel cells are made up of three distinct parts - the anode, the electrolyte, and the cathode, which create energy from hydrogen and oxygen. As hydrogen enters the fuel cell, on the anode side, the hydrogen molecule is oxidized. The polymer electrolyte membrane that separates the anode from the cathode is permeable for hydrogen cations, but not electrons. The electrons flow to an external circuit, which is how electrical current is produced by the fuel cell.

The polymer exchange membrane is preferred in vehicle prototypes due to its ability to be sufficiently efficient at low operating temperatures (Bakker 2011). More than $80 \%$ of fuel cells in production in 2013 were PEM fuel cells (Barbir 2013). The hydrogen fuel cell system design is based on currently available commercial technology. Ballard Power Systems, Inc., is a leading fuel cell manufacturer that produces fuel cells for a variety of applications. The Ballard FCVelocity-HD6 fuel cell, which is designed for bus applications, was chosen as the model for the concept design of the fuel cell system because it is a leading commercial technology for bus applications, which is transferable to railway applications. The operating and physical characteristics of this technology are listed in Table 5. Fuel cells marketed for specific applications, such as mobile or telecom applications, are generally interchangeable with alternative uses (Hoffrichter 2013). The selection of the Ballard FCVelocity-HD6 fuel cell, originally intended for bus applications, is appropriate given sufficient power output. Just as battery technology is generally interchangeable among applications, fuel cells may be interchangeable given an appropriate bundle design (fuel cell unit power output and number of units). The manufacturer lists the fuel cell efficiency as $60-71 \%$; therefore, a conservative case and optimistic case were employed in the wellto-wheel analysis.

TABLE 5.

Parameters of Ballard FCVelocity-HD6 Fuel Cell

\begin{tabular}{|l|c|}
\hline \multicolumn{1}{|c|}{ Parameter } & Value \\
\hline Power rating & $150 \mathrm{~kW}$ \\
\hline DC voltage & $230-800 \mathrm{~V}$ \\
\hline Maximum current & $320 \mathrm{~A}$ \\
\hline Weight & $404 \mathrm{~kg}$ \\
\hline Volume & $23.3 \mathrm{ft}^{3}$ \\
\hline Fuel consumption & $1.3-2.5 \mathrm{~g} / \mathrm{s}$ \\
\hline Fuel cell efficiency & $60-71 \% \mathrm{LHV}$ \\
\hline Lifetime & 12,000 hours \\
\hline
\end{tabular}

Source: Ballard Power Systems, Inc., 2012

\section{Results}

The remaining efficiency factors consider energy losses through the locomotive drive train and the transmission of electricity for electric trains. The energy chain and the respective efficiency factors for the existing electric S70 and the concept hydrogen train 
are shown in Tables 6 and 7. Neither table includes improved efficiency due to regenerative braking, as that is figured separately and is based on physical characteristics of the journey. However, a hydrogen-hybrid propulsion system may offer greater regenerative braking efficiency than an electric propulsion system. Regenerative braking for an electric train captures approximately $57.6 \%$ of energy available to be regenerated ( $80 \%$ of total is captured due to blended braking, $90 \%$ due to traction efficiency, and $80 \%$ available for use because of receptive catenary) (International Union of Railways 2002). A hydrogen-hybrid train would have a similar $80 \%$ efficiency factor for blended braking and $90 \%$ traction efficiency but would not be constrained by unreceptive catenary. As a result, a hydrogen-hybrid could close the well-to-wheel efficiency gap that separates electric and hydrogen propulsion systems by a factor that is a function of catenary receptivity.

TABLE 6.

Well-to-Wheel Efficiency Factors Using LHV for Electric

Train

\begin{tabular}{|c|c|}
\hline Well-to-Tank (Well-to-Pantograph) & LHV Efficiency \\
\hline Energy at source & $100 \%$ \\
\hline Weighted efficiency of North Carolina electricity mix ${ }^{1}$ & $39.0 \%$ \\
\hline Grid transmission ${ }^{2}$ & $94 \%$ \\
\hline Catenary transmission ${ }^{3}$ & $92.5 \%$ \\
\hline Total well-to-tank (well-to-pantograph) & $33.9 \%$ \\
\hline Tank-to-Wheel (Pantograph-to-Wheel) & LHV Efficiency \\
\hline Feed cable $^{3}$ & $95 \%$ \\
\hline Transformer ${ }^{3}$ & $95 \%$ \\
\hline Control system and electronics ${ }^{3}$ & $97.5 \%$ \\
\hline Electric motors $^{3}$ & $95 \%$ \\
\hline Transmission $^{3}$ & $96 \%$ \\
\hline Traction auxiliaries $^{4}$ & $93 \%$ \\
\hline Total tank-to-wheel (pantograph-to-wheel) & $74.6 \%$ \\
\hline Total Well-to-Wheel & $25.3 \%$ \\
\hline
\end{tabular}

${ }^{1}$ Computed previously in Table 2.

${ }^{2}$ U.S. Energy Information Administration 2014.

${ }^{3}$ Hoffrichter 2013.

${ }^{4}$ Computed from assumed auxiliary load of $35 \mathrm{~kW}$, Traction Auxiliaries Efficiency $=(1-(35 \mathrm{~kW} * 0.7406$ hours)/375 kWh). 
TABLE 7.

Well-to-Wheel Efficiency Factors Using LHV for Hydrogen Train

\begin{tabular}{|c|c|}
\hline Well-to-Tank & LHV Efficiency \\
\hline Energy at source & $100 \%$ \\
\hline Weighted efficiency of feedstock ( $91.7 \%$ natural gas and $8.3 \%$ electricity) ${ }^{1}$ & $47.7 \%$ \\
\hline Steam methane reforming $\left(\mathrm{H}_{2} \text { production and compression }\right)^{2}$ & $71.4 \%$ \\
\hline Total well-to-tank & $34.0 \%$ \\
\hline Tank-to-Wheel & LHV Efficiency \\
\hline Fuel cell power plant ${ }^{3}$ & $60-71 \%$ \\
\hline Electric motors $^{4}$ & $92 \%$ \\
\hline Transmission $^{4}$ & $95 \%$ \\
\hline Motor auxiliaries ${ }^{4}$ & $99 \%$ \\
\hline Traction auxiliaries $^{5}$ & $93.72 \%$ \\
\hline Total tank-to-wheel & $48.7-57.6 \%$ \\
\hline Total Well-to-Wheel & $16.6-19.6 \%$ \\
\hline
\end{tabular}

${ }^{1}$ Computed previously in Table 3.

${ }^{2}$ Inclusive of compression efficiency (Elgowainy, Han and Zhu 2013).

${ }^{3}$ Efficiency of Ballard FCVelocity-HD6, 60-71\% LHV (Ballard Power Systems Inc 2012).

${ }^{4}$ Hoffrichter 2013.

${ }^{5}$ Computed from assumed auxiliary load of $35 \mathrm{~kW}$, Traction Auxiliaries Efficiency $=(1-(35 \mathrm{~kW} * 0.74$ hours)/411 kWh). No negligible difference between hydrogen and hydrogen-hybrid.

The LHV efficiency factors not associated with hydrogen technology are sourced from existing literature and are not specific to the $\mathrm{S} 70$ rolling stock or a hydrogen-powered light rail vehicle. Hydrogen production is assumed to be via a distributed SMR; therefore, an efficiency factor for pipeline or trucking transportation is omitted in Table 7.

By comparing the well-to-wheel efficiency chart for electric and hydrogen trains, the differences are apparent. For the well-to-tank, both propulsion technologies have a nearly identical efficiency factor of $34 \%$. The feedstock energy production efficiency for hydrogen is greater than that of electricity because of the large share of natural gas that is required for SMR. As the electricity mix transitions away from coal-produced power in the coming years, the difference in feedstock energy production efficiency will decrease. To make up for this loss in feedstock efficiency superiority, the hydrogen production method has room to improve. Regardless of the hydrogen-to-electricity conversion method (electrolysis or SMR), advances in technology will improve hydrogen production efficiency and make hydrogen power more competitive with electricity. Feedstock energy production for both electric and hydrogen propulsion systems will advance in parallel; hydrogen's additional chemical conversion $\left(\mathrm{H}_{2}\right.$ to $\left.\mathrm{H}_{2} \mathrm{O}\right)$ has room for improvement.

Technological advances in electrolysis or SMR will enable hydrogen-powered technologies to close the efficiency gap with electric propulsion. The hydrogen and electric trains tank-to-wheel is nearly comparable albeit one major difference. The efficiency of the energy pathway for a hydrogen train is severely limited by the efficiency of a fuel cell. This, unlike hydrogen production methods, cannot be substituted by alternatives and, therefore, is dependent on technological advancements. In total, the efficiency superiority of an electric train is clearly demonstrated with current technology, but hydrogen and 
hydrogen-hybrid trains will close the gap in the coming years and may make the technology a more viable alternative.

\section{Conclusions}

The results presented in this paper are presumed to be representative of hypothetical hydrogen-powered light rail trains for operation in Charlotte, North Carolina. Since hydrogen-powered light rail trains are not in use in the United States, several assumptions were made that have significant implications on the results. The well-to-wheel analysis is dependent on the assumed energy production methods and is specific to the study area of North Carolina. True operating characteristics and efficiency values may differ from what is presented, but the magnitude of difference is not expected to be large. Consequently, the research is useful in demonstrating the relative performance of hydrogen-powered trains with electric-powered trains.

The hydrogen fuel cell used in this research touts impressive $60-71 \%$ fuel cell efficiency, which only a few years ago would be a great feat. However, without accounting for any additional losses, such as traction auxiliaries, the overall vehicle efficiency of a hydrogen train is already less than that of an electric train. Until improvements are made in hydrogen fuel cell efficiency, hydrogen power must compete in feedstock generation. The feedstock generation and hydrogen generation gives hydrogen-power flexibility to reduce overall energy demand and energy emissions.

From an energy demand perspective, the energy at the wheels of the hydrogen train balloons by $502 \%$ (or $410 \%$ for the optimistic case) to the required feedstock energy. These values far exceed the $295 \%$ increase in energy demand from the wheels to the well for an electric train. A hydrogen train will not reduce energy consumption of light rail operations based on current technologies. Two processes restrict the hydrogen train energy pathways - the production and compression of hydrogen and the production of current in the fuel cell. Improvement in the efficiency of the fuel cell power plant can reduce energy demand and emission production. Additionally, replacing SMR with electrolysis that is powered by renewable energy removes the efficiency factor and emission production. The total well-to-wheel efficiency could improve from $16.6 \%$ (or $19.6 \%$ for the optimistic case) to a value comparable to the electric train's $25.3 \%$ well-to-wheel efficiency.

Feedstock efficiency is a sizable portion of the well-to-tank analysis and has an effect on the overall results. The results presented here are not applicable to all cities, but may be easily interpreted to a different context. Light rail in Cleveland, Ohio, for example, is powered by an electricity mix with a $64 \%$ coal share. The difference in electricity mix between Ohio and North Carolina, all else equal, results in an overall well-to-wheel efficiency of $24.6 \%$ and $25.3 \%$, respectively. Alternatively, a city with a more favorable electricity mix, such as Portland, Oregon, has the opposite effect on the overall well-to-wheel efficiency. Oregon's electricity comprises a $72 \%$ hydroelectric share, which nearly doubles North Carolina's electric train well-to-wheel efficiency factor to $50.3 \%$. For settings where the electricity mix is primarily composed of coal, electric light rail systems compound the energy inefficiency while settings with large hydroelectric shares take advantage of the hydroelectric energy efficiency. 
The well-to-wheel analysis is just one part of a variety of analysis methods that provide decision-makers and planners sufficient information necessary to make objective decisions. The objective in using new power technologies for light rail, such as hydrogen power, should be sufficiently analyzed to ensure that it is met. Often, hydrogen power is presented as a green technology and, therefore, should perform well in a well-to-wheel analysis. The well-to-wheel analysis specifically provides insight into system efficiencies. Obviously, the current hydrogen power technologies assumed for this study do not meet the current technology standard (electric catenary). However, a litany of other technology assumptions and evaluation metrics could be made that would impact the results.

The well-to-wheel analysis results demonstrate the critical importance of hydrogen production and fuel cell technology development. These two areas represent the greatest potential for energy efficiency gain for hydrogen-powered trains. The efficiency of fuel cell is improving as research and development finds improved methods, which will bode well for hydrogen power in the future. Hydrogen production methods also have some potential efficiency gains, but the greatest asset associated with hydrogen production is the flexibility.

An evaluator or planner could impact the results by changing the hydrogen production method. For this study, decentralized SMR hydrogen production was assumed because it is currently the most practical production method for a case study in North Carolina. However, different objectives may yield different scenarios. For example, water electrolysis may be more appropriate in a situation in which surplus renewable energy is available. In this case, lower efficiency values may be tolerated for the expected reduction in emissions. Most importantly, the underlying objective should guide the design of new applications of technology.

There may be practical limitations to the adoption of renewable energy technology in rail transit, such as the maximization of usable floor space for passengers. A hydrogen-powered light rail (e.g., Charlotte's Blue Line Extension, operating a 3-car consist for 20.5 hours per day) would require approximately $1,391 \mathrm{ft}^{3}$ of volume (in general, space) for 25 fuel cells and 125 hydrogen storage vessels (Washing 2014). This volume requirement is nearly identical to the estimated volume for the diesel-electric articulated railcar's power module and excess roof volume of $1,329 \mathrm{ft}^{3}$ (Hoffrichter 2013). The difference in usable passenger space between a hydrogen and diesel-electric passenger train is expected to be negligible. On the other hand, an electric light rail is without an on-board power plant, which reduces the amount of available space for hydrogen technology. However, the nearly $1,400 \mathrm{ft}^{3}$ of necessary volume for hydrogen fuel cells and storage vessels for a three-car consist could certainly be added to the roof of the light rail, without significant changes to the overall size. A Siemens S70 with a three-car consist is approximately 280 feet long, which would only require a frontal cross section area increase of $5 \mathrm{ft}^{2}$ to accommodate the hydrogen-related volume needs (Washing 2014). The light rail manufacturer, however, would most certainly meet such design challenges in the event that a market for hydrogen light rail develops.

Economics are always an important part of the adoption of new technologies, which is another avenue for hydrogen power to surpass current technologies. While the hydro- 
gen-powered light rail train does not demonstrate energy efficiency superiority over electric catenary under the made assumptions, other decision criteria, such as emissions and economics, may prove to be more important criteria. As always, the objective of the application should determine the course of action.

\section{Acknowledgments}

Many thanks to the Infrastructure, Design, Environment, and Sustainability (IDEAS) Center at UNC Charlotte for research funding and the opportunity to travel to the University of Birmingham (UK) to partake in the 2014 Railway Challenge. The authors also thank Dr. Stuart Hillmansen and Dr. Andreas Hoffrichter of the University of Birmingham who were instrumental in preparing the first author to complete the simulations and providing assistance throughout the research.

\section{References}

Air Products. 2013. "Steam Methane Reformer Overview." Air Products. http://www.airproducts.com/ /media/Files/PDF/industries/energy-hydrogen-steam-methane-reformer-datasheet.pdf, accessed June 10, 2014.

altenergymag.com. 2013. "TIG/M Modern Street Railways Delivering World's Greenest Streetcars to Aruba in Island's Transition to 100\% Sustainability." March. http:// www.altenergymag.com/news/2013/03/27/tigm-modern-street-railways-deliveringworld39s-greenest-streetcars-to-aruba-in-island39s-transition-to-100-sustainability/28761, accessed June 8, 2014.

Alternative Fuels Data Center. 2014. "Hydrogen Production and Distribution." http:// www.afdc.energy.gov/fuels/hydrogen_production.html, accessed May 27, 2014.

Argonne National Laboratory. 2010. "Technical Assessment of Compressed Hydrogen Storage Tank Systems for Automotive Applications." Argonne National Laboratory. September. http://www.ipd.anl.gov/anlpubs/2011/02/68305.pdf, accessed July 6, 2014.

Bakker, S. 2011. Competing Expectations: The Case of the Hydrogen Car. Oisterwijk, Netherlands: Uitgeverij BOXPress.

Bakker, S. 2010. "Hydrogen Patent Portfolios in the Automotive Industry - The Search for Promising Storage Methods." International Journal of Hydrogen Energy, 35 (13): 6784-6793.

Ballard Power Systems, Inc. 2012. Product Portfolio. September. http://www.ballard.com/ files/PDF/ProductPortfolio.pdf.

Barbir, F. 2013. PEM Fuel Cells: Theory and Practice. Waltham, MA: Academic Press.

Barral, K., and H. Barthelemy. 2006. "Hydrogen High Pressure Tanks Storage: Overview and New Trends Due to H2 Energy Specifications and Constraints." June. http://www. 
cder.dz/A2H2/Medias/Download/Proc\%20PDF/PARALLEL\%20SESSIONS/[S12]\%20 Storage\%20-\%20Gaseous\%20Hydrogen/15-06-06/331.pdf, accessed July 27, 2014.

Bossel, U., and B. Eliasson. 2003. "Energy and the Hydrogen Economy." Alternative Fuels Data Center. http://www.afdc.energy.gov/pdfs/hyd_economy_bossel_eliasson.pdf, accessed June 4, 2014.

Clarke Energy. 2013. "Heating Value." January. http://www.clarke-energy.com/2013/heating-value/, accessed August 4, 2014.

Elgowainy, A., Jeongwoo Han, and Hao Zhu. 2013. "Updates to Parameters of Hydrogen Production Pathways in GREET." Systems Assessment Group, Energy Systems Group, Argonne National Laboratory.

Hoffrichter, Andreas. 2013. "Hydrogen as an Energy Carrier for Railway Traction." Dissertation, the Birmingham Centre for Railway Research and Education, University of Birmingham.

International Union of Railways. 2002. "Regenerative Braking in DC Systems." http://www. railway-energy.org/static/Regenerative_braking_in_DC_systems_103.php, accessed July 30, 2014.

Miller, A. R., and D. L. Barnes. 2002. Advanced Underground Vehicle Power and Control Fuelcell Mine Locomotive." Vehicle Projects LLC, U.S. DOE Hydrogen Program Review.

Miller, A. R., K. S. Hess, D. L. Barnes, D.L., and T. L. Erickson. 2007. "System Design of a Large Fuel Cell Hybrid Locomotive." Journal of Power Sources, 173: 93.

Ogden, Joan M. 2002. "Review of Small Stationary Reformers for Hydrogen Production." http://www.afdc.energy.gov/pdfs/31948.pdf, accessed August 4, 2014.

SUSY. 2012. "Hydrogen-Energy for the Future." http:// www.susy-power.de/en/service/ technology-know-how.html, accessed July 30, 2014.

TIAX LLC. 2007. "Full Fuel Cycle Assessment: Well-to-Wheels Energy Inputs, Emissions, and Water Impacts." Consultant Report, California Energy Commission, Cupertion, CA.

Washing, E. M. 2014. "Hydrogen Power for Light Rail Operation: Operational Feasibility and Practical Applicability." Thesis, University of North Carolina at Charlotte.

U.S. Department of Energy. 2012. "Lower and Higher Heating Values of Fuels. January. http://hydrogen.pnl.gov/cocoon/morf/hydrogen/site_specific/fuel_heating_calculator, accessed August 12, 2014.

U.S. Department of Energy, Energy Efficiency, and Renewable Energy. 2014. "Hydrogen, Fuel Cells, \& Infrastructure Technologies Program. April. https://www.fueleconomy. gov/feg/animation/swfs/fuelcellframe.html, accessed June 12, 2014.

U.S. Energy Information Administration. 2014. How Much Electricity is Lost in Transmission and Distribution in the United States. May. http://www.eia.gov/tools/faqs/faq. cfm?id=105\&t=3, accessed August 1, 2014. 
U.S. Energy Information Administration. 2014. "State Profiles and Energy Estimates." http://www.eia.gov/state/, accessed October 17, 2014.

\section{About the Authors}

E. MATtheW WASHING (ewashin5@uncc.edu) is a first-year Ph.D. student at the University of North Carolina at Charlotte in the Infrastructure and Environmental Systems (INES) program. He received his B.S. in Finance (cum laude) from University of North Carolina, Wilmington in 2012 and M.S. in Engineering from the University of North Carolina at Charlotte in 2014. His research interests include public transportation, traffic operations, and transportation safety.

SRInivas S. Pulugurtha (sspulugurtha@uncc.edu) is a Professor of Civil \& Environmental Engineering Department and Director of Infrastructure, Design, Environment and Sustainability (IDEAS) Center at the University of North Carolina at Charlotte. He received his Ph.D. in Civil Engineering from the University of Nevada, Las Vegas in 1998. 